\title{
Associations of Pulmonary Fibrosis with Peripheral Blood Th1/Th2 Cell Imbalance and EBF3 Gene Methylation in Uygur Pigeon Breeder's Lung Patients
}

\author{
Chao Wu Zujin Luo ${ }^{\mathrm{b}}$ Baosen Pang ${ }^{\mathrm{b}}$ Wenyi Wang ${ }^{\mathrm{a}}$ Mingqin Deng ${ }^{\mathrm{a}}$ Rong Jin ${ }^{\mathrm{a}}$ \\ Xirennayi Muhataer ${ }^{a}$ Yafang Li $^{\mathrm{a}}$ Qifeng Li ${ }^{\mathrm{c}}$ Xiaohong Yang ${ }^{\mathrm{a}}$ \\ aDepartment of Respiratory and Critical Care Medicine, People's Hospital of Xinjiang Uygur \\ Autonomous Region, Urumqi, ${ }^{b}$ Department of Respiratory and Critical Care Medicine, Beijing \\ Engineering Research Center of Respiratory and Critical Care Medicine, Beijing Institute of Respiratory \\ Medicine, Beijing Chao-Yang Hospital, Capital Medical University, Beijing, 'Xinjiang Institute of \\ Pediatrics, People's Hospital of Xinjiang Uygur Autonomous Region, Urumqi, China
}

\section{Key Words}

Ebf3 gene • Pigeon breeder's lung $•$ Hypersensitivity pneumonitis $•$ Pulmonary fibrosis $•$ Uygur

\begin{abstract}
Background/Aims Pigeon breeder's lung (PBL) results from Th1/Th2 cell imbalance. B cells inhibit the immune activity of Th1, and EBF3 is a key B cell factor. This study explored the relationship between EBF3 and Th1/Th2 imbalance in chronic PBL cases complicated with pulmonary fibrosis (PF). Methods Twenty Uygur PBL+PF patients, 20 pigeon breeders without $\mathrm{PBL}$ or PF, and 20 healthy individuals without pigeon breeding history constituted the patient I, negative control, and normal control groups, respectively. Peripheral blood specimens and case backgrounds were collected between June 2016 and March 2017. EBF3 gene methylation was analyzed by matrix assisted laser desorption ionization-time of flight mass spectrometry. To compare different mechanisms of PF progression in PBL, samples from 20 Uygur PBL patients without PF (at acute and sub-acute stages) were collected between October 2017 and February 2018, constituting the patient II group. EBF3 mRNA expression was evaluated by real-time polymerase chain reaction. IFN- $\gamma$, IL-4 and IL-10 expression and Th1/Th2 imbalance in PBL were evaluated by enzyme-linked immunosorbent assay and flow cytometry. Results CpG-2 and general methylation rates in the patient I group were lower than those in the control groups $(\mathrm{P}<0.017)$. The level of EBF3 mRNA expression in the patient I group was significantly higher than that in any other group. Compared with the control groups, the patient I group showed a significantly higher level of IL-4, whereas the patient II group showed a significantly lower level. IL-10 was also expressed more highly in the patient I group than in any other group $(\mathrm{P}<0.01)$. Flow cytometry showed INF- $\gamma$ dominance (Th1 cytokine) in PBL at the acute/
\end{abstract}

Chao Wu and Zujin Luo contributed equally to this work.

Qifeng Li and

Xiaohong Yang
Xinjiang Institute of Pediatrics, People's Hospital of Xinjiang Uygur Autonomous Region

No. 91 Tianchi Road, Tianshan District, 830001 Urumqi, (China)

E-Mail liqiqi521@sina.com or yangxh_16@163.com 
sub-acute stage and IL-4 dominance (Th2 cytokine) at the chronic stage after PF occurred. The general methylation rate was negatively correlated with the mRNA level, with the latter being positively correlated with the IL-10 level and number of pigeons bred in the past 3 months. IL-4 expression was negatively correlated with INF- $\gamma$ but positively correlated with PF area and duration of pigeon breeding history. Conclusions After PF occurs in chronic PBL, the inflammation type changes from Th1 dominance to Th2 dominance. During PBL development, IL-10 increases before IL-4 does, which may be associated with EBF3 hypomethylation and the involvement of B lymphocytes.

(C) 2018 The Author(s)

Published by S. Karger AG, Basel

\section{Introduction}

Pigeon breeder's lung (PBL), a type of hypersensitivity pneumonitis (HP) [1], is usually attributed to inhalation of pigeon dropping products, such as excreta, feathers and serum; subsequent intense immune responses are induced, resulting in pulmonary alveolitis. HP is an interstitial lung disease for which the common outcome is pulmonary fibrosis (PF) [2].

Based on animal experiments, Th2 dominance occurs as an immune response in PF cases developing from PBL [3], which had long been believed to be a Th1/Th2-imbalance disease featuring Th1 dominance [4]. Previous studies by our research group have revealed that the acute stage of PBL is caused by Th1 imbalance, characterized by increases in the levels of INF- $\gamma$ and IL- 2 and decreases in those of IL-4 and Il-10 [5, 6]. One study among cases of HP caused by farmer's lung showed that in acute stages, activated Th1 cells secrete IL-2 and IFN- $\gamma$ during the immune response. According to a clinical study on HP, the expression levels of proinflammatory factors, such as IL-2 and IFN- $\gamma$, in bronchoalveolar lavage fluid and TNF- $\alpha$ in serum are markedly increased $[4,7]$. However, according to an animal study, Th2 cell dominance and PF occur together in chronic stages, and IL-4 is highly expressed [8]. To the best of our knowledge, no report on the high expression of Th2 in PBL with PF has been published to date. Th1 is inhibited by B cells [9], and EBF3 is an essential factor for B cell maturation [3]. Nonetheless, the role of B cells in Th1/Th2 imbalance, i.e., the change from Th1 dominance to Th2 dominance, in PBL remains unclear.

Uygurs are residents of Xinjiang, China, and the genome of this population contains 11 types of genes of Turkish, Arab, Western European and Southeast Asian ethnic origin; Islam is the common religious faith among these people. Our previous study reported a high morbidity rate among Uygur, which may be attributed to their custom of pigeon breeding. Among PBL cases, 63.6\% evolved into interstitial pneumonia [10], and long-term exposure to allergens can result in multiple diseases, including PF, breathing failure, pulmonary artery hypertension (PAH) and pulmonary heart disease [11]. Patients with repeated coughing or shortness of breath are often misdiagnosed with asthma, tracheitis, pneumonia, which causes the PF outcome, pulmonary heart disease and respiratory failure. In general, patients referred for treatment to large hospitals are in a severe condition with irreversibly impaired cardio-pulmonary function [12]. Indeed, an investigation of pigeon breeder clubs showed an HP prevalence of $8 \%-30 \%$ among breeders [13]. In our previous study, the prevalence rate of HP in Uygur populations was 8\%, and in most of these cases, HP evolved into PF because the patients did not receive proper treatment [14].

Whole-genome methylation preliminary screening has been performed in 4 Uygur PBL patients and 4 Uygur pigeon breeders without PBL using the Illumina method, with abnormal EBF3 gene methylation found among the Uygur PBL patients. In this study, the role of gene methylation in abnormal EBF3 expression in PBL patients with PF and the relationship between EBF3 and Th1/Th2 imbalance in PBL were investigated to reveal the molecular biological mechanisms of Th1/Th2 imbalance and PF in chronic-stage Uygur PBL patients. 


\section{Cellular Physiology Cell Physiol Biochem 2018;47:1141-1151 and Biochemistry Published online: June 18, $2018 \quad \begin{aligned} & \text { DOI: 10.1159/000490208 } 2018 \text { The Author(s). Published by S. Karger AG, Basel } \\ & \text { www.karger.com/cpb }\end{aligned}$ Wu et al.: EBF3 Gene Methylation in Pigeon Breeder's Lung Patients}

\section{Materials and Methods}

\section{Patients}

Twenty Uygur patients with a confirmed diagnosis of PBL with PF between October 2015 and March 2016 at First People's Hospital of Kashi Prefecture and People's Hospital of Xinjiang Uygur Autonomous Region were collected as the patient I group. In addition, another 20 acute/sub-acute PBL patients without PF who were confirmed in a survey conducted in the Kashi district between October 2017 and February 2018 constituted the patient II group. The ages of the patients varied from 20 to 80, and gender was unrestricted. The diagnostic criteria for PBL were those of HP, and the criteria suggested by Schuyler et al. were widely applied [10]. Grading of lesion areas in the lungs of PBL patients was performed according to Muller grades $>1$. Exclusion criteria included the following: (1) interstitial lung diseases; chronic bronchitis; acute respiratory distress syndrome; autoimmune diseases and malignant tumors; and (2) other supersensitivity diseases or lung diseases with diffuse lesions. The clinical characteristics of the patients are summarized (for all online suppl. material, see www.karger.com/doi/10.1159/000490208) in the supplementary file.

The negative control group included 20 Uygur pigeon breeders who had bred pigeons for more than 3 years and had no clinical manifestations; the normal control group included 20 individuals with normal physical examinations and no history of pigeon breeding. The ages and genders of both the negative and normal control groups matched those of the patient groups.

This study was conducted in accordance with the Declaration of Helsinki. Approval was obtained from the Ethics Committee of People's Hospital of Xinjiang Uygur Autonomous Region, and informed consent was obtained from each participant.

\section{Case collection}

General background information including gender, age, smoking history, and pigeon breeding history along with clinical materials such as lab diagnostic results, lung function, and image examination results were collected for each participant. Fasting peripheral venous blood samples were collected into anticoagulative tubes. After centrifugation, white blood cells were isolated and stored at $-80{ }^{\circ} \mathrm{C}$ for subsequent mRNA detection.

\section{DNA preparation}

DNA was extracted from blood samples using a Wizard Genomic DNA purification Kit (Promega; Madison, WI, USA), quantified with a spectrophotometer, and assessed by agarose gel electrophoresis. Electrophoretic genomic bands were usually larger than $20 \mathrm{~kb}$. Qualified DNA was transferred to 384-well plates after being adjusted to $50 \mathrm{ng} / \mu \mathrm{L}$ and stored at $-20^{\circ} \mathrm{C}$.

\section{RNA preparation}

Total RNA was extracted from blood samples using a Qiagen RNeasy Mini Kit (Qiagen; Düsseldorf, Germany) and reverse transcribed with a Transcriptor cDNA Synthesis Kit (Roche; Basel, Switzerland).

\section{Primer design}

Primers were designed based on methylation sites in the EBF3 gene and synthesized by CapitalBio (Beijing, China). The EBF3 gene (cg12129080) contains 4 CpG sites, which were marked as CpG_1, CpG_2, CpG_3 and CpG_4/5. The targeted EBF3 gene sequence was TGCAGCTTAATGAGGGGCACATGTGTGCAAAGCCTTAACTTC ATTACTCCTGCGTGTCAACATATACAAGAGAAATGTGT bnGTACAGGTCATCCATTACTCGGAACAGCACCGAGCCC TCTCTCTTCACCTCCCTTTGTTGATGAGCCAGGAGCCATAA ATTAATCCCGTTCTGTGGCTCGGGGAAGGACCAAGGT GTTAAAATCTC.

To evaluate EBF3 mRNA expression, the primers used were forward 5'-TGTAGTTTAATGAGGGGTATATGTGTGT-3' and reverse 5'-AAAATTTTAACACCTTAATCCTTCCC-3', with an expected PCR product of $206 \mathrm{bp}$.

\section{Polymerase chain reaction (PCR) amplification}

PCR amplification was performed using a kit from SEQUENOM (San Diego, CA, USA). The amplification conditions consisted of $94{ }^{\circ} \mathrm{C}$ for $12 \mathrm{~min}$, followed by 10 cycles of $93^{\circ} \mathrm{C}$ for $50 \mathrm{sec}, 62{ }^{\circ} \mathrm{C}$ (decreases of 0.5 ${ }^{\circ} \mathrm{C}$ per cycle) for $48 \mathrm{sec}$ and $72{ }^{\circ} \mathrm{C}$ for $1 \mathrm{~min}, 35 \mathrm{cycles}$ of $94{ }^{\circ} \mathrm{C}$ for $45 \mathrm{sec}, 56^{\circ} \mathrm{C}$ for $48 \mathrm{sec}$ and $72{ }^{\circ} \mathrm{C}$ for 1 min, and a final step of $72{ }^{\circ} \mathrm{C}$ for $3 \mathrm{~min}$ and a $4{ }^{\circ} \mathrm{C}$ hold. PCR products were identified by $2 \%$ agarose gel electrophoresis.

\section{KARGER}




\section{Cellular Physiology Cell Physiol Biochem 2018;47:1141-1151 \begin{tabular}{l|l} 
and Biochemistry Published online: June 18, 2018 & $\begin{array}{l}\text { C } 2018 \text { The Author(s). Published by S. Karger AG, Basel } \\
\text { www.karger.com/cpb }\end{array}$
\end{tabular}}

Wu et al.: EBF3 Gene Methylation in Pigeon Breeder's Lung Patients

Alkaline phosphatase (SAP), in vitro transcription and RNase digestion

SAP, in vitro transcription and RNase digestion protocols were conducted according to the MassCLEAVE Kit instruction manual (SEQUENOM).

Sample spotting and mass spectrographic analysis

Using a MassARRAYNanodispenser RS1000 (SEQUENOM), purified samples were spotted onto a 384-format SpectroCHIP and detected with MassARRAY Compact System (SEQUENOM). SpectroCHIP was designed and run based on mass spectrographic matrix-assisted laser desorption/ionization-time of flight (MALDI-TOF) technology; data were analyzed using EpiTYPER (SEQUENOM).

\section{EBF3 mRNA expression in peripheral blood}

EBF3 mRNA expression levels in peripheral blood samples were evaluated using real-time PCR with a QuantiFast SYBR Green PCR Kit. Primer design was based on the EBF3 mRNA sequence in GenBank (NM001005463): forward and reverse EBF3 sequences of 5'-GACCCGTCAGAAGCCACTC-3' and 5'-TGCAGCCCGTCAAAGAAG-3', respectively.

\section{Detection of IFN- $\gamma$ and IL-4 in serum}

The serum expression levels of IFN- $\gamma$ and IL-4 were detected using an enzyme-linked immunosorbent assay (ELISA) Kit (eBioscience) according to the manual; each sample was analyzed in duplicate.

Isolation and culture of peripheral mononuclear cells (PBMCs)

PBMCs were isolated from blood samples using Ficoll (GE Healthcare, Uppsala, Sweden). After centrifugation at $2000 \mathrm{rpm}$ for $20 \mathrm{~min}$, PBMCs were extracted in buffy coats, washed twice, centrifuged again at $1500 \mathrm{rpm}$ for $10 \mathrm{~min}$ at room temperature and incubated in 96-well plates using RPMI-1640 (Life Technologies, Paisley, UK) supplemented with 10\% fetal bovine serum (Gibco BRL Co. Ltd., NY, USA); each well contained $10^{6}$ cells. After extracted pigeon exfoliated products $(8 \mu \mathrm{L})$ were added to the wells, the cultures were incubated for $24 \mathrm{hr}$ at a final concentration of $0.5 \mathrm{mg} / \mathrm{mL}$.

\section{Analysis of Th1 and Th2 cells via flow cytometry}

After collecting cell cultures, cells were suspended in $200 \mu \mathrm{L}$ RPMI 1640 supplemented with $10 \%$ FBS $\left(2 \times 10^{5}\right.$ cells $)$ and transferred to flow cytometry tubes $(12 \times 75 \mathrm{~mm})$. APC-H7-conjugated anti-human CD3 and FITC-conjugated anti-human CD4 monoclonal antibodies (BD Bioscience PharMingen, San Jose, CA, USA) were added to the tubes. The samples were then incubated in the dark at room temperature for 15-30 min, washed with $1 \mathrm{~mL}$ staining buffer, centrifuged at $500 \times \mathrm{g}$ for $5 \mathrm{~min}$, and fixed. The membranes were permeabilized and incubated in the dark at $2-8^{\circ} \mathrm{C}$ for $40-50 \mathrm{~min}$. After washing twice with phosphatebuffered saline (PBS), the samples were resuspended in $100 \mu \mathrm{L}$ PBS. PE/Cy7-conjugated anti-human IFN- $\gamma$ and APC-conjugated anti-human IL-4 monoclonal antibodies (BD Bioscience PharMingen) were added, and the samples were incubated in the dark at $2-8{ }^{\circ} \mathrm{C}$ for $40-50 \mathrm{~min}$. Isotype controls were provided to enable correct compensation and confirm antibody specificity. Stained cells were analyzed with a FACS Canto TMII FCM flow cytometer and pre-installed FACSD software via Readme (BD Bioscience PharMingen).

\section{Statistical analyses}

Data analyses were performed using SPSS 17.0 software. Comparisons of methylation rates among the patient I, negative control and normal control groups were based on the Kruskal-Wallis method, and P values $<0.05$ were considered statistically significant. Pairwise comparisons among the groups were performed using the Mann-Whitney method. Because repeated hypothesis testing increases the probability of type I errors, correction of the inspection level was required. In this study, $\alpha^{\prime}=0.017$ and $\mathrm{P}<0.017$ were considered statistically significant. One-way analysis of variance was used to compare EBF3 mRNA expression levels in serum among the four groups, and P values $<0.05$ were considered statistically significant. SNK-q was used in pairwise comparisons among the groups. Analysis of TGF- $\beta$ in bronchoalveolar lavage fluid was performed using t-tests, with P values $<0.05$ considered statistically significant. Correlation analyses were conducted using Pearson's correlation coefficients. Figures were created using GraphPad Prism 6 software. 


\section{Cellular Physiology Cell Physiol Biochem 2018;47:1141-1151 \begin{tabular}{l|l} 
and Biochemistry POI: 10.1159/000490208 & $\begin{array}{l}\text { C) } 2018 \text { The Author(s). Published by S. Karger AG, Basel } \\
\text { www.karger.com/cpb }\end{array}$
\end{tabular} \\ Wu et al.: EBF3 Gene Methylation in Pigeon Breeder's Lung Patients}

\section{Results}

\section{General information}

Age and gender were not significantly different among the four groups. No member of the four groups had a smoking history. According to the Muller method, the PF area was graded on six levels (level 0-level 5), with higher grades indicating larger areas. Blind evaluations of PF areas were performed by three radiologists, and at least two equal scores among the groups were deemed qualified. If this criterion was not met, reappraisal was required (Table 1).

\section{Analysis of EBF3 (cg12129080) methylation}

EBF3 (cg12129080) methylation analysis was performed for the patient I, negative control and normal control groups. Four CpG sites (CpG_1, CpG_2, CpG_3, CpG_4/5) were analyzed for detection, and three sites were found (Fig. 1). The methylation rates of CpG_1 and $\mathrm{CpG}_{-} 4 / 5$ in the three groups did not differ significantly $(\mathrm{P}>0.05)$, though differences in $\mathrm{CpG}_{-} 2$ among the three groups were statistically significant $(\mathrm{P}<0.05)$. In the pairwise comparison of CpG_2 among the three groups, the EBF3 methylation rate in the patient I group was significantly lower than that in the negative and normal control groups $(\mathrm{P}<0.017)$, though the rates in the negative and normal control groups were not significantly different $(P>0.017)$. The distribution of the general methylation rate among the three groups demonstrated statistical significance $(\mathrm{P}<0.05)$. In pairwise multiple comparison analysis of the rate of EBF3 gene methylation, that of the patient I group was lower than those of the negative and normal control groups, with statistical significance $(\mathrm{P}<0.017)$. Conversely, the difference between the negative and normal control groups was not statistically significant $(\mathrm{P}>0.017)$. The results are summarized in Tables 2 and 3 . The detailed data regarding methylation are summarized (see online suppl. material) in the supplementary file.

In this study, 5 CpG sites were evaluated, among which 4 were found. Because the same results were observed for sites 4 and 5 , we used the designation CPG-4/5. The color of the patient I group was light, indicating a low rate of methylation, and the dark colors of the negative and normal control groups indicated a high degree of methylation.

\section{EBF3 mRNA expression}

Real-time PCR showed that the levels of EBF3 mRNA expression in the patient groups were higher than those in the negative and normal control groups $(\mathrm{P}<0.01)$, with the patient I group being significantly higher than the patient II group. However, differences between EBF3 mRNA expression in the negative and normal control groups were not significant (Fig. 2A).

Table 1. General background information on the patients in each of the four groups

\begin{tabular}{|c|c|c|c|c|}
\hline & Patient I & Patient II & Negative & Normal control \\
\hline Age (year), $\bar{x} \pm s$ & $50.24 \pm 13.68$ & $46.96 \pm 13.44$ & $51.27 \pm 11.12$ & $52.66 \pm 10.74$ \\
\hline $20-40$ years & 4 & 3 & 5 & $4 / 20.00$ \\
\hline 41-60 year & 7 & 10 & 8 & $8 / 40.00$ \\
\hline$>60$ years & 9 & 7 & 7 & $8 / 40.00$ \\
\hline Gender (M/F) & $12 / 8$ & $13 / 7$ & $11 / 9$ & $10 / 10$ \\
\hline \multicolumn{5}{|l|}{ Pigeon breeding years } \\
\hline$<1$ & 0 & 20 & 0 & 0 \\
\hline $1-3$ & 6 & & 0 & 0 \\
\hline$>3$ & 14 & & 20 & 0 \\
\hline No experience & 0 & & 0 & 20 \\
\hline \multicolumn{5}{|l|}{ Number of pigeons bred } \\
\hline$<50$ & 4 & & 0 & \\
\hline$>50$ & 7 & 4 & 7 & \\
\hline$>100$ & 9 & 16 & 13 & \\
\hline None & 0 & 0 & 0 & 20 \\
\hline \multicolumn{5}{|l|}{ PF area (Muller) } \\
\hline 1 score: lesion $<5 \%$ & 3 & - & - & - \\
\hline 2 scores: lesion $6-24 \%$ & 7 & - & - & - \\
\hline 3 scores: lesion $25-49 \%$ & 5 & - & - & - \\
\hline 4 scores: $50-75 \%$ & 3 & - & - & - \\
\hline 5 scores: $>75 \%$ & 2 & - & - & - \\
\hline
\end{tabular}


Investigation of Th1/ Th2 imbalance in PBL via ELISA

INF- $\gamma$ expression in the patient II group was significantly higher than in the other groups $(\mathrm{P}<0.001)$. In addition, the level of IL-4 in the patient I group was significantly higher than in the other groups, whereas the IL-4 level in the patient II group was significantly lower than in the normal and negative control groups $\quad(\mathrm{P}<0.001) . \quad \mathrm{IL}-10$ in the patient I group was higher than in the patient II, negative and normal control groups $(\mathrm{P}<0.001)$, though the levels were not significantly different ( $P>0.05$ ) (Fig. 2B-D).

Flow cytometry analysis of Th1 and Th2 cells

The results for the two $\mathrm{T}$ helper cell subgroups based on flow cytometry are shown in Fig. 3. The percentage of Th2 cells in the patient I group and that of Th1 cells in the patient II group was significantly higher (both $\mathrm{P}<0.05$ ) than in the negative and normal control groups.

\section{Correlation analysis between EBF3 and pigeon breeding time, pigeon number, $P F$ area and Th1/Th2-related factors}

PF areas, based on the Muller method, were graded on 6 levels (from 0 to 5), with higher scores indicating larger areas. Pigeon breeding times were graded on 3 levels ( $<1$ year, 1-3 years and $>3$ years), and the numbers of pigeons bred in the past 3 months were graded on 3 levels $(<50,51-100$, and $>100)$.

In the patient I group, the general EBF3 methylation rate was negatively correlated with the level of its mRNA (correlation coefficient=-0.889). mRNA expression of EBF3 showed positive correlations with both pigeon breeding time (correlation coefficient $=0.223$ ) and number (correlation coefficient $=0.762$ ). The $\mathrm{PF}$ area was positively correlated with the mRNA level (correlation coefficient $=0.362$ ), and the level of mRNA expression was negatively

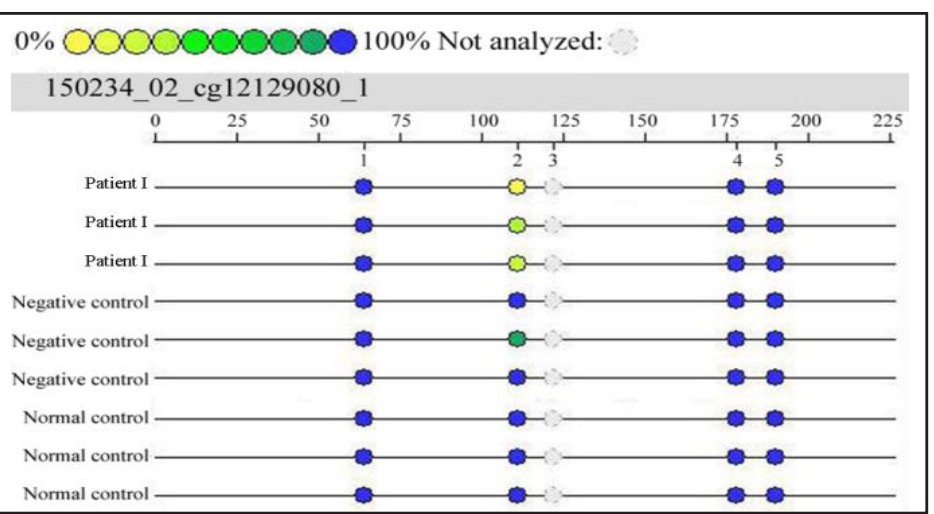

Fig. 1. Screen shot of the mass spectrum analysis of the EBF3 gene (cg12129080).

Table 2. Median (P50) and range interquartile (P25, P75) for each $\mathrm{CPG}$ site and the general methylation rate of the EBF3 gene

\begin{tabular}{lcccc}
\hline CPG & Patient I & Negative & $\begin{array}{c}\text { Normal } \\
\text { control }\end{array}$ & General \\
\hline CPG_1 & $0.93(0.92,0.95)$ & 0.94 & 0.94 & 0.94 \\
& & $(0.93,0.95)$ & $(0.93,0.94)$ & $(0.93,0.94)$ \\
CPG_2 & $0.64(0.38,0.90)$ & 0.90 & 0.93 & 0.90 \\
& & $(0.83,0.94)$ & $(0.90,0.96)$ & $(0.77,0.94)$ \\
CPG-4/5 & $0.94(0.93,0.95)$ & 0.94 & 0.94 & 0.94 \\
& & $(0.93,0.95)$ & $(0.91,0.94)$ & $(0.93,0.95)$ \\
General methylation & $0.83(0.71,0.92)$ & 0.92 & 0.93 & 0.92 \\
& & $(0.89,0.94)$ & $(0.92,0.94)$ & $(0.85,0.94)$ \\
\hline
\end{tabular}

Table 3. Comparisons of each $\mathrm{CpG}$ site and general methylation rates among three groups. A, the patient I group. B, the negative control group. C, the normal control group. $Z$, the $Z$ value based on pairwise comparison (the rank-sum test was performed due to heterogeneity of variance)

\begin{tabular}{cccccccccc}
\hline \multirow{2}{*}{ CPG site } & \multicolumn{2}{c}{$\mathrm{A} / \mathrm{B} / \mathrm{V}$} & \multicolumn{2}{c}{$\mathrm{A} / \mathrm{B}$} & \multicolumn{2}{c}{$\mathrm{A} / \mathrm{V}$} & \multicolumn{2}{c}{$\mathrm{B} / \mathrm{V}$} \\
& $\mathrm{X} 2$ & $\mathrm{P}$ & $\mathrm{Z}$ & $\mathrm{P}$ & $\mathrm{Z}$ & $\mathrm{P}$ & $\mathrm{Z}$ & $\mathrm{P}$ \\
\hline CPG-1 & 1.258 & 0.742 & -0.911 & 0.383 & -0.474 & 0.978 & -0.474 & 0.616 \\
CPG-2 & 12.991 & 0.002 & -2.732 & 0.006 & -1.684 & 0.007 & -1.335 & 0.212 \\
CPG-4/5 & 4.706 & 0.177 & -1.234 & 0.217 & -1.010 & 0.259 & -0.791 & 0.560 \\
General methylation & 9.730 & 0.008 & -2.449 & 0.014 & -1.739 & 0.005 & -0.791 & 0.560
\end{tabular}




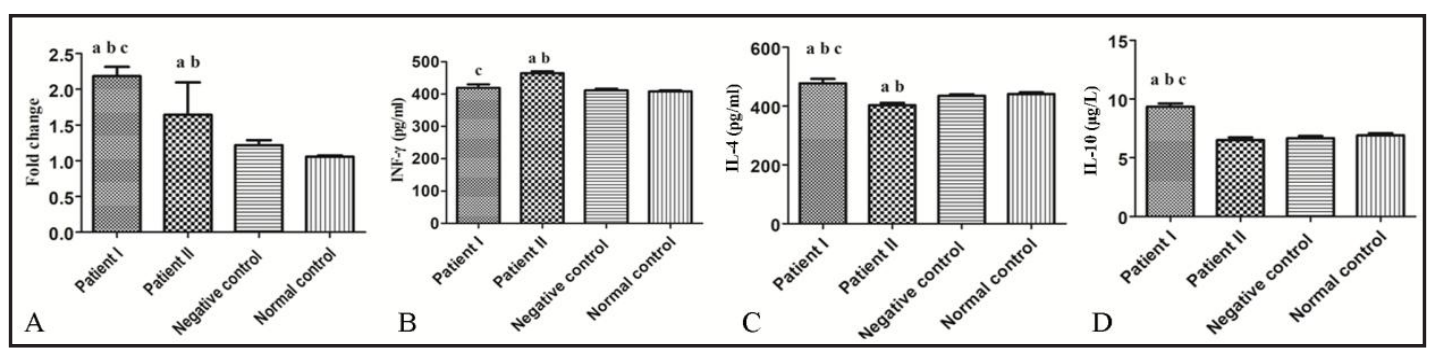

Fig. 2. Expression of EBF3 mRNA and the levels of IFN- $\gamma$, IL-4 and IL-10 in the patient, negative and normal control groups. (A) EBF3 mRNA. (B) IFN- $\gamma$. (C) IL-4. (D) IL-10. Data are shown as mean values. Notes: a, $\mathrm{P}<0.05$ vs. the normal control group; $\mathrm{b}, \mathrm{P}<0.05$ vs. the negative control group; and $c, \mathrm{P}<0.05$ vs. the patient II group.

correlated with IFN- $\gamma$ (correlation coefficient $=-0.366$ ). Moreover, the level of mRNA expression was positively correlated with IL-4 (correlation coefficient $=0.557$ ), and expression of IL-4 was negatively correlated with IFN- $\gamma$ (correlation coefficient $=-0.859$ ). Expression of IL-4 was positively correlated with the PF area (correlation coefficient $=0.733$ ), pigeon number (correlation coefficient $=0.511$ ) and pigeon breeding time (correlation coefficient $=0.711$ ).

\section{Discussion}

Although the pathogenesis of PBL is known to be closely related to long-term exposure to exogenous antigens and immune reactions are known to mediate lung injury, the cellular immunological mechanism of HP remains unclear [15]. In the early stages of the immune response, proteins in pigeon dropping products, such as feathers and dander, are recognized and phagocyted by macrophages in the lung, forming an immunocomplex with IgG and activating

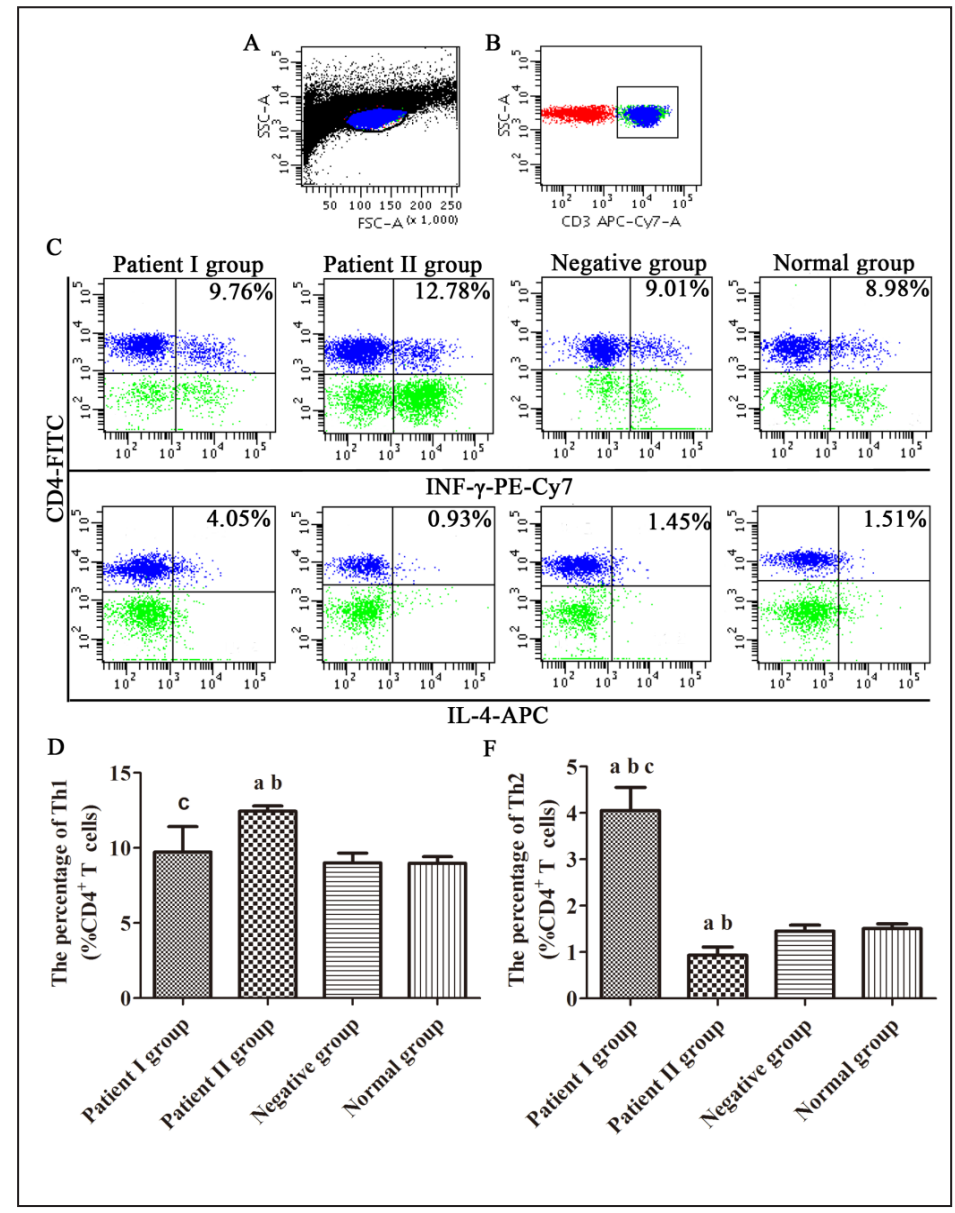

Fig. 3. Portions of Th1 and Th2 cells. Cells from the patient I, patient II, and negative and normal groups were treated with pigeon dropping extracts in vitro for $24 \mathrm{~h}$. Th1 and Th2 percentages were analyzed by fluorescence-activated cell sorting (FACS). (A) Lymphocytes. FSC/ SSC were gated. (B) CD3+T lymphocytes. SSC/CD3 were gated. (C) Intracellular expression of IFN $-\gamma$ and IL-4 by CD3+CD4+ T cells. (D) Histogram of Th1. (E) Histogram of Th2. Data are shown as mean percentages. Notes: $\mathrm{a}, \mathrm{P}<0.05$ vs. the normal control group; $\mathrm{b}, \mathrm{P}<0.05$ vs. the negative control group; and c, $\mathrm{P}<0.05$ vs. the patient II group.

\section{KARGER}


macrophages via the complement pathway [16]. These activated macrophages then release chemotactic factors, such as interleukin-8 (IL-8) and macrophage inflammatory protein- $1 \alpha$ (MIP-1 $\alpha$ ), which consequentially induce the macrophages to proliferate at the inflammatory site. Furthermore, antigen processing by macrophages can promote conversion of CD4+ Th0 cells to Th1 cells, and activated Th1 cells contribute to the immune response via production of IL- 2 and IFN- $\gamma$ [4]. Clinical research on HP has shown significantly increased levels of IL-2 and IFN- $\gamma$ in bronchoalveolar lavage fluid and TNF- $\alpha$ in serum, all of which are proinflammatory factors [7]. A study on farmer's lung, another type of HP, revealed that large numbers of lymphocytes and high levels of IL-2 are present in the bronchoalveolar lavage fluid of people exposed to allergens, which might result in lymphocyte accumulation in the lung. Moreover, serum soluble IL-2 receptor was found to be expressed at a high level [17], and PF and Th2 dominance were observed when the disease evolved to the chronic stage; IL-4 was also produced by Th2 cells at a higher level [8]. In our previous study, Th1associated cytokines were found to be highly expressed in PBL patients. In the current study, significantly increased IL-4 levels were observed in PBL patients with PF compared to the control group, and expression of IL-4 was correlated with pigeon breeding time and the level of PF. However, the levels of IFN- $\gamma$ expression did not differ significantly among the groups, which may have been attributed to a gradual decrease in IL-2 along with evolution of the disease. IFN- $\gamma$ expression was negatively correlated with IL-4 expression and therefore also with PBL evolution. Furthermore, the percentage of Th1 cells gradually decreased, whereas that of Th2-associated cytokines gradually increased. Although the mechanism remains unclear, B cells may function in the immune response by inhibiting Th1 cells [7].

From a traditional point of view, B cells display two types of activity: B cells can differentiate into plasmocytes, which secrete antibodies in humoral immunity, and produce cytokines, which regulate other immune cells. Thus, B cells should have a positive role in adaptive immunity. However, in a 1974 study based on an animal model, B cells were found to play a negative role in the immune response by inhibiting delayed-type hypersensitivity [18]. A 1996 study found that defective mouse B cells were not able to recover from experimentally induced autoimmune diseases, indicating the potential inhibitory role of $\mathrm{B}$ cells in inflammation and eliciting a public focus on inhibitory B cells [19]. In actuality, a series of B cells, named regulatory B cells (Bregs) by Mizoguchi and Bhan, exert an inhibitory role in various autoimmune diseases, such as experimental autoimmune encephalitis (EAE), collagen-induced arthritis (CI) and inflammatory bowel diseases [20-22]. In immunerelated diseases, IL-10 and TGF- $\beta$ have been shown to be key factors mediating the inhibitive immunoregulation of Bregs [23]. In a mouse arthritis model, T2-MZP B cells secreted IL-10 and inhibited T cell production of IFN- $\gamma$ during controlled disease evolvement. In an EAE mouse model, all activated B cells, including transitional form B cells, follicular B cells, MZ B cells, peritoneal cavity B1 type B cells and lymph gland B cells, were able to secrete IL-10 to control the inflammatory T cell response [24]. Based on a mouse CIA model, B10 cells can inhibit the proliferation and differentiation of IL-17-secreting CD4+ T cells mediated by IL-10 [25]. In our previous study, levels of IL-10 and IL-4 were decreased in the serum and bronchoalveolar lavage fluid of PBL patients in the acute stage of the disease [5]. In the current investigation, we selected PBL patients without PF as a study group and found that compared with the negative and normal control groups, these patients had decreased levels of IL-4, whereas no significant differences in IL-10 level were found among the groups. After PF developed, serum IL-10 and IL-4 levels increased, which might provide insight into the dynamic characteristics of IL in PBL patients. IL-4 is primarily excreted by Th2 cells, whereas IL-10 can be excreted by both Th2 cells and B lymphocytes. Our study showed that the increase in IL-10 occurred before that of IL-4, which may be attributed to the immunization role of B cells in PBL patients, though the possibility of experimental error cannot be completely excluded. Furthermore, B cells have a negative regulatory function via decreased accumulation of NK and CD8+ T cells. Our previous study found that the Th1-related cytokine 


\section{Cellular Physiology Cell Physiol Biochem 2018;47:1141-1151

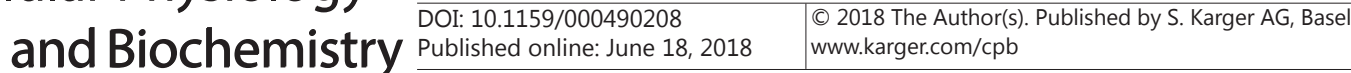

Wu et al.: EBF3 Gene Methylation in Pigeon Breeder's Lung Patients

IL-2 is expressed at a high level in the acute stages of PBL. In the present study, Th1-related cytokines gradually decreased in chronic-stage PBL patients with PF, whereas Th2-related cytokines increased to become dominant in the immune response. In addition, EBF3, a B cell maturation-related factor, was found to exhibit a low level of methylation but a high level of mRNA expression. These data indicate that the Th1/Th2 imbalance changed from Th1 dominance to Th2 dominance as PBL evolved, which might be related to the role of $B$ cells in the immune response. TGF- $\beta$ is an essential regulator of regulatory B cells, and in our previous study, PF in PBL was related to the TGF- $\beta /$ Smad signaling pathway, with TGF- $\beta$ being expressed at high levels in PBL patients with PF [14]. However, the B cell-related pathogenesis of PBL remains to be investigated.

This study found the mRNA level of EBF3 to be negatively correlated with the rate of methylation but positively correlated with the number of pigeons bred in the past 3 months, Th2-related cytokine expression, and IL-10 level. However, the EBF3 mRNA level was not closely related with the PF area or pigeon breeding time. As IL-10 is a key factor for B cells to exert their immune function, our results suggest that EBF3 may participate in the development of PBL by regulating B lymphocytes, which needs to be confirmed by EBF3 gene interference in animal experiments to observe changes in B cells. Furthermore, this study showed that Th2 cytokines are positively correlated with the pigeon breeding time and PF area, demonstrating the association between Th2 cytokines and PF in PBL patients. Nonetheless, we found that expression of Th2 cytokines was notably increased, even in patients who had recently bred only a small number of pigeon. Presumably, this phenomenon was associated with the relatively large population breeding pigeons in the surrounding area. We also found that lung inflammation still proceeded in some PBL patients who had moved away from the local region for various reasons, such as a change in employment, indicating that inflammatory damage in PBL patients does not rely on persistent contact with allergens. Therefore, identification of inflammation reaction-blocking targets remains an urgent task for PBL intervention. Methylation is a major route of gene regulation, with high methylation rates associated with down-regulated gene expression and low methylation rates with up-regulated gene expression [14]. The level of EBF3 expression was related to allergen contact frequency and disease evolution; although the number of pigeons bred indicated the allergen contact frequency and the level of inflammation, the PF area did not indicate the level of inflammation. In this study, 20 PBL patients with PF in Kashi, Xinjiang responded to a questionnaire, and the screened patients were subjected to lung computed tomography (CT) scans and pulmonary function examinations to confirm their diagnosis. Although Th1 dominance was found at the acute stage of PBL in our previous study, Th2 dominance in chronic-stage PBL patients with PF was observed in the current study. However, because this study was originally performed based on an unexpected and interesting finding, it suffered from deficiency in grouping. To compare different mechanisms involved in progression to PF in PBL, we at a late stage included acute/sub-acute PBL patients without PF as the patient II group. Therefore, it was difficult to perform the EBF3 methylation experiment under the same conditions using this group. Regardless, in the early stage of this study, we found that EBF3 methylation had a strong negative correlation with EBF3 mRNA. Accordingly, we performed PCR to assess EBF3 mRNA expression in this group. In addition, although we performed mRNA detection, ELISA, and flow cytometry for the patient II group using the same instruments and reagents from the same companies, a larger same size or animal experiments are still needed to reduce experimental errors as much as possible.

This study is the first to show that by increasing the mRNA expression levels of the gene itself, low levels of EBF3 methylation are involved in progression of PF in Uygur PBL patients. After PF occurs in chronic PBL patients, the inflammation type changes from Th1 dominance to Th2 dominance. During the development of PBL, the increase in IL-10 occurs before that in IL-4, which may be associated with EBF3 hypomethylation and the participation of B lymphocytes. 


\section{Cellular Physiology Cell Physiol Biochem 2018;47:1141-1151 \begin{tabular}{l|l} 
and Biochemistry Published 10.1159/000490208 & $\begin{array}{l}\text { (c) } 2018 \text { The Author(s). Published by S. Karger AG, Basel } \\
\text { www.karger.com/cpb }\end{array}$
\end{tabular}}

Wu et al.: EBF3 Gene Methylation in Pigeon Breeder's Lung Patients

\section{Acknowledgements}

This study was supported by the Fund of Young Scientific and Technological Talents From Health and Family Planning Commission of Xinjiang Uygur Autonomous Region (Title: Investigation of correlation between macrophage and Th1/Th2 imbalance in pigeon breeder lung patient of Uygur, No. 2017Y01).

The funding body has no roles in the design of the study and collection, analysis, and interpretation of data and in writing the manuscript.

\section{Disclosure Statement}

The authors declare no conflicts of interest.

\section{References}

1 Lacasse Y, Girard M, Cormier Y: Recent advances in hypersensitivity pneumonitis. Chest 2012;142:208-217.

2 García de Alba C, Buendia-Roldán I, Salgado A, Becerril C, Ramírez R, González Y, Checa M, Navarro C, Ruiz V, Pardo A, Selman M: Fibrocytes contribute to inflammation and fibrosis in chronic hypersensitivity pneumonitis through paracrine effects. Am J Respir Crit Care Med 2015;191:427-436.

-3 Park SH, Kim SK, Choe JY, Moon Y, An S, Park MJ, Kim DS: Hypermethylation of EBF3 and IRX1 genes in synovial fibroblasts of patients with rheumatoid arthritis. Mol Cells 2013;35:298-304.

-4 Guo N, Xu Y, Cao Z: Absinthin attenuates LPS-induced ALI through MIP-1alpha-mediated inflammatory cell infiltration. Exp Lung Res 2015;41:514-524.

5 Wang W, Wu C, Yang X: Cytokines level in Uygur pigeon breeder's lung disease patients. Chinese General Practice 2014;17:3837-3839.

-6 Yu B, Yang X, Li F, Wu C, Wang W, Ding W: Significance of Foxp3+CD4+ regulatory T cells in the peripheral blood of Uygur patients in the acute and chronic phases of pigeon breeder's lung. Bosn J Basic Med 2017;17:17-22.

-7 Li W, Liu YJ, Zhao XL, Shang SQ, Wu L, Ye Q, Xu H: Th1/Th2 cytokine profile and its diagnostic value in mycoplasma pneumoniae pneumonia. Iran J Pediatr 2016;26:3807-3815.

8 Mitaka K, Miyazaki Y, Yasui M, Furuie M, Miyake S, Inase N, Yoshizawa Y: Th2-biased immune responses are important in a murine model of chronic hypersensitivity pneumonitis. Int Arch Allergy Immunol 2011;154:264-274.

-9 Liu F, Lu X, Dai W, Lu Y, Li C, Du S, Chen Y, Weng D, Chen J: IL-10-producing B cells regulate T helper cell immune responses during 1, 3- $\beta$-glucan-induced lung inflammation. Front Immunol 2017;6:414.

10 Yang XH, Wu C, Wang WY, Pang BS: Correlation of IL-10 and IL-2 single gene polymorphisms with the susceptibility to pigeon breeder's lung in Chinese Uygur population. Int J Clin Exp Pathol 2016;9:47294737.

11 Soumagne T, Pana-Katatali H, Degano B, Dalphin JC: Combined pulmonary fibrosis and emphysema in hypersensitivity pneumonitis. BMJ Case Rep 2015;152:198-212.

12 Wu C, Chen Y, Yang X, Wang W, Pang B: Correlation of macrophage inflammatory protein-1alpha single gene polymorphisms with the susceptibility to pigeon breeder's lung in chinese uygur population. Int J Clin Exp Med 2015;8:13732-13739.

13 Ito T, Sugino K, Satoh D, Muramatsu Y, Sano G, Sato K, Sakaguchi S, Isobe K, Sakamoto S, Takai Y, Hata Y, Shibuya K, Uekusa T, Kurosaki A, Homma S: Bird fancier's lung which developed in a pigeon breeder presenting organizing pneumonia. Intern Med 2010;49:2605-2608.

14 Wu C, Ding W, Li Q, Wang W, Deng M, Jin R, Pang B, Yang X: The correlation between pulmonary fibrosis and methylation of peripheral Smad3 in cases of pigeon breeder's lung in a Chinese Uygur population. Oncotarget 2017;8:43104-43113.

15 Suhara K, Miyazaki Y, Okamoto T, Yasui M, Tsuchiya K, Inase N: Utility of immunological tests for birdrelated hypersensitivity pneumonitis. Respir Investig 2015;53:13-21. 


\section{Cellular Physiology Cell Physiol Biochem 2018;47:1141-1151

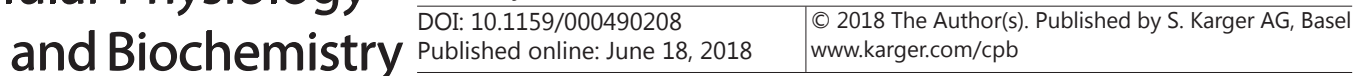 \\ Wu et al.: EBF3 Gene Methylation in Pigeon Breeder's Lung Patients}

16 Chiba S, Tsuchiya K, Akashi T, Ishizuka M, Okamoto T, Furusawa H, Tateishi T, Kishino M, Miyazaki Y, Tateishi U, Takemura T, Inase N: Chronic hypersensitivity pneumonitis with a usual interstitial pneumonialike pattern: Correlation between histopathological and clinical findings. Chest 2016;149:1473-1481.

17 Villar A, Muñoz X, Sanchez-Vidaurre S, Gómez-Ollés S, Morell F, Cruz MJ: Bronchial inflammation in hypersensitivity pneu monitis after antigen-specific inhalation challenge. Respirology 2014;19:891-899.

18 Neta R, Salvin SB: Specific suppression of delayed hypersensitivity: the possible presence of a suppressor B cell in the regulation of delayed hypersensitivity. J Immunol 1974;113:1716-1725.

19 Wolf SD, Dittel BN, Hardardottir F, Janeway CA Jr: Experimental autoimmune encephalomyelitis induction in genetically B cell-deficient mice. J Exp Med 1996;184:2271-2278.

-20 Ray A, Basu S: Regulatory B cells in experimental autoimmune encephalomyelitis (EAE). Methods Mol Biol. 2014;11:243-255.

21 Carter NA, Rosser EC, Mauri C: Interleukin-10 produced by B cells is crucial for the suppression of Th17/ Th1 responses, induction of T regulatory type 1 cells and reduction of collagen-induced arthritis. Arthritis Res Ther 2012;14: R32.

22 Vadasz Z, Haj T, Kessel A, Toubi E: B-regulatory cells in autoimmunity and immune mediated inflammation. FEBS Lett 2013;587: 2074-2078.

23 Ding T, Yan F, Cao S, Ren X: Regulatory B cell: New member of immunosuppressive cell club. Hum Immunol 2015;76:615-621.

24 Yang M, Deng J, Liu Y, Ko KH, Wang X, Jiao Z, Wang S, Hua Z, Sun L, Srivastava G, Lau CS, Cao X, Lu L: IL-10producing regulatory B10 cells ameliorate collagen-induced arthritis via suppressing Th17 cell generation. Am J Pathol 2012;180:2375-2385.

-25 Flores-Borja F, Bosma A, Ng D, Reddy V, Ehrenstein MR, Isenberg DA, Mauri C: CD19+CD24hi CD38hi B cells maintain regulatory T cells while limiting TH1 and TH17 differentiation. Sci Transl Med 2013;5:173183. 